\title{
Association of chemokine and chemokine receptor expression with the invasion and metastasis of lung carcinoma
}

\author{
YAN LIU ${ }^{1,2}$, BING-QUAN WU ${ }^{1}$, HUA GENG $^{2}$, MEI-LIN XU ${ }^{2}$ and HAO-HAO ZHONG ${ }^{1}$ \\ ${ }^{1}$ Department of Pathology, Peking University Health Science Center, Beijing 100191; \\ ${ }^{2}$ Department of Pathology, Tianjin Chest Hospital, Tianjin 300051, P.R. China
}

Received August 14, 2014; Accepted May 29, 2015

DOI: $10.3892 / \mathrm{ol} .2015 .3402$

\begin{abstract}
The chemokine system has been reported to be utilized and manipulated by tumor cells in order to promote local tumor growth and distant dissemination. The present study aimed to investigate the expression of three chemokine ligand-receptor axes in lung carcinoma tissues. Tumor and healthy normal tissue samples were obtained from 120 lung carcinoma patients following surgical resection. Immunohistochemistry and reverse transcription quantitative polymerase chain reaction were used in order to identify the protein and messenger (m)RNA expression of chemokines, including chemokine (C-X-C motif) ligand (CXCL)12/stromal cell-derived factor (SDF)-1, CXCL8/interleukin (IL)-8, chemokine (C-C motif) ligand (CCL)19 and CCL21, and the corresponding chemokine receptors, chemokine (C-X-C motif) receptor (CXCR)4, CXCR1, CXCR2 and chemokine (C-C motif) receptor (CCR)7, respectively. The results revealed that compared with the normal lung tissues, lung carcinoma tissues expressed significantly higher mRNA levels of CXCL12/SDF-1, CXCR4, CXCL8/IL-8, CXCR2, CCL19 and CCR7 $(\mathrm{P}<0.01)$. In four histological subtypes, adenocarcinoma presented dominant expression of CXCR4, CXCR2, CXCL8/IL-8 and CCL19 (P<0.05). In addition, it was demonstrated that tumor staging was inversely correlated with chemokine receptor CCR7 and CXCR2 mRNA expression as well as positively correlated with CXCL12/SDF-1, CXCL8/IL-8 and CCL19 mRNA levels $(\mathrm{P}<0.05)$. Lymph node metastasis presented a positive correlation with CXCR4, CXCR2 and CXCL8/IL-8 expression and a negative correlation with CCL19 and CCR7 expression $(\mathrm{P}<0.05)$. Furthermore, vascular invasion was more prevalent in patients with higher expression levels of CXCR4, CCR7 or CCL19 ( $\mathrm{P}<0.01)$. In conclusion, these data suggested that the ligand-receptor interaction of CXCL8-CXCR2, CXCL12-CXCR4 and CCL19-CCR7 may be involved in the tumorigenesis of lung
\end{abstract}

Correspondence to: Dr Yan Liu, Department of Pathology, Peking University Health Science Center, 38 Xueyuan Road, Beijing 100191, P.R. China

E-mail: laylaly@126.com

Key words: chemokine, chemokine receptor, lung carcinoma, metastasis, invasion carcinoma. Higher expression levels of chemokines and lower expression of chemokine receptors indicated poor tumor staging. The CXC chemokine receptors, CXCR4 and CXCR2, promoted lymphatic metastasis through the activation of their specific ligands, while CCL19 and its receptor CCR7 had an essential role in hematogenous metastasis of lung carcinoma.

\section{Introduction}

Lung cancer is the second most prevalent type of malignancy and the primary cause of cancer-associated mortality worldwide (1). Numerous advances have been made in diagnostic, surgical and staging techniques for cancer over the past decade, as well as in the development of novel chemotherapy and radiotherapy treatments (2). Following initial tumorigenesis, cancers may progress via the following three distinct pathways: Local invasion into adjacent structures; lymphatic spread to regional lymph nodes; and the hematogenous spreading of distant metastases (2).

The chemokine family consists of 48 chemotactic cytokines, which interact with chemokine receptors under physiological and pathological conditions in order to regulate immune cell trafficking (3). The presence of a limited number of chemokines and chemokine receptors has been reported in cancer tissues (4). In tumor cells, the chemokine system is utilized and manipulated in order to promote local tumor growth and distant dissemination. The promotion of tumor cell growth, survival and neo-angiogenesis occurs through autocrine and paracrine interactions between chemokines and chemokine receptor loops in the tumor microenvironment (5). At distant sites, endogenous tissue-produced chemokines attract and navigate tumor cells expressing chemokine receptors in order for metastasis to occur (3-5).

Chemokine (C-X-C motif) receptor (CXCR) 4 is the most prevalent type of chemokine receptor expressed by malignant tumors, the only ligand for which is chemokine (C-X-C motif) ligand (CXCL)12/stromal cell-derived factor (SDF)-1 (3). Previous studies regarding CXCL12-CXCR4 focus on its pathologic role and the potential therapeutic implications of targeting this axis for the treatment of lung cancer $(2,3,6,7)$. In addition, CXCL8/interleukin-8 (IL-8), a potent angiogenic and autocrine growth factor, was reported to be associated with metastasis of lung cancer (8). The IL-8 receptors, CXCR1 and CXCR2, have been identified in numerous tumor cells; however, the presence of 
these receptors has not yet been reported in lung cancer. Chemokine (C-C motif) receptor (CCR)7, which is the receptor for two major chemokines, chemokine (C-C motif) ligand (CCL) 19 and CCL21, was also demonstrated to have an important role in tumor metastasis and was associated with poor prognosis $(9,10)$. The aim of the present study was to investigate the role of three chemokine ligand-receptor pairs, CXCL12-CXCR4, CXCL8-CXCR1/CXCR2, CCL19/CCL21-CCR7, in the malignant progression and metastasis of lung carcinoma.

\section{Materials and methods}

Human tissue collection. Lung carcinoma and non-malignant lung tissues were obtained from patients who underwent pulmonary lobe resection or pneumonectomy at Tianjin Chest Hospital (Tianjin, China) between 2007 and 2009. Of the 120 cancer patients studied, 79 were men and 41 were female, with an average age at the time of surgery of $59.7 \pm 6.53$ years (range, 31-79 years). Clinicopathological information was recorded, including patient characteristics, histological subtype, tumor grade and tumor-node-metastasis (TNM) staging results. The identification of tumor types was performed by two professional pathologists. Of these patients, 30 cases were adenocarcinomas (Adc), 54 cases were squamous cell carcinomas (Scc), 24 cases were adenosquamous carcinomas (Asc) and 12 cases were combined small-cell carcinoma (Csc). The stages of tumors were estimated according to the 7 th edition of the new TNM staging system suggested by the International Association for the Study of Lung Cancer in 2009 (11). Written informed consent was obtained from the patients. All procedures involving participants in the study were approved by Peking University Institutional Review Board (approval no. IRB00001052-10004; the approval no. is the same as that of a previous study by the same authors).

Immunohistochemistry. All tumor and normal control tissue samples were formalin fixed and paraffin embedded. Sections of 4- $\mu \mathrm{m}$-thick were then cut onto glass slides and dewaxed in xylene, then rehydrated through graded alcohols $(100,95,85$ and $70 \%)$. Antigen retrieval was performed using citrate buffer $(10 \mathrm{mM}$, pH 6.0) in a pressure cooker (model EPC450; Elecpro Electric Appliance Holding Co., Ltd, Guangdong, China; heated to $117.5^{\circ} \mathrm{C}$ for $3 \mathrm{~min}$ and then cooled to room temperature). Following antigen retrieval, $0.3 \% \mathrm{H}_{2} \mathrm{O}_{2}$ in phosphate buffer solution was employed to block endogenous peroxidase activity in the sections. The aforementioned chemical reagents were purchased from Sinopharm Chemical Reagent Beijing Co., Ltd. (Beijing, China). Following treatment with protein-blocking serum to block non-specific binding, the sections were incubated overnight at $4^{\circ} \mathrm{C}$ with the following monoclonal mouse anti-human antibodies (dilution, $25 \mu \mathrm{g} / \mathrm{ml}$; R\&D Systems Europe, Abingdon, United Kingdom): CXCR1 (clone 79018), CXCR2 (clone 48311), CXCL8 (clone 6217), CXCR4 (clone 44716), CXCL12/SDF-1 (clone 51505), CCL19 (clone 54909), CCL21 (clone 59106) and CCR7 (clone 150503). A streptavidin/biotin detection reagent kit with 3, 3'-diaminobenzidine tetrahydrochloride was used for signal detection and Harris hematoxylin was used to counter-stain slides. The reagents for immunohistochemical analysis, including the buffer, serum, detection kit, DAB and hematoxylin, were obtained from Maixin
Biotech Co., Ltd. (Fuzhou, China). For each staining, negative control slides were processed without the primary antibody.

The mean percentage of positive tumor cells was determined in at least five fields of vision (magnification, x200) using Leica DM1000 microscope (Leica Microsystems, Solms, Germany). All slides were evaluated by experienced pathologists who reviewed the slides together and reached a consensus. The staining of chemokines and chemokine receptors was primarily located in the cytoplasm or cytomembrane. Tumors were assigned scores based on the percentage of positively-stained cells and the intensity of immunostaining. The scoring for the percentage of positively-stained tumor cells was as follows: $0,<5 \% ; 1,5-25 \% ; 2,25-50 \% ; 3,50-75 \%$; and $4,>75 \%$. Immunostaining intensity was scored as follows: 0 , none; $1+$, weak; $2+$, moderate; and $3+$, intense. The two scores were multiplied together to achieve a weighted score for each case. Cases with weighted scores of 0 or 1 were defined as negative; cases with scores of $\geq 2$ were defined as positive.

$R N A$ extraction and reverse transcription quantitative polymerase chain reaction (RT-qPCR) analysis. Within $10 \mathrm{~min}$ after surgery, tissues without necrosis and hemorrhage were dissected from the tumor, followed by flash freezing in liquid nitrogen and storing at $-70^{\circ} \mathrm{C}$. Total cellular RNA was extracted from frozen samples using TRIzol reagent (Invitrogen Life Technologies, Carlsbad, CA, USA) according to the manufacturer's instructions. A Nanodrop 2000 (Thermo Scientific Inc., Wilmington, DE, USA) was used to determine RNA quality. RNA $(2 \mu \mathrm{g})$ from each sample was used for complementary (c) DNA production using Moloney murine leukemia virus reverse transcriptase and random hexamers (Promega Corp., Madison, WI, USA). Amplification of control GAPDH was performed using diluted cDNA (1:10) in order to determine RT efficiency as well as RNA integrity. RT-qPCR was performed in a total volume of $50 \mu \mathrm{l}$ containing 1X GoTaq flexi buffer, $5 \mathrm{mM} \mathrm{MgCl} 2,200 \mu \mathrm{M}$ each deoxynucleotide, 2.5 Units GoTaq DNA polymerase (Promega Corp.), $500 \mathrm{nM}$ primers (as shown in Table I), SYBR-Green I (1:20,000; Invitrogen Biotechnology Co., Ltd., Shanghai, China) and $2.5 \mu \mathrm{l}$ diluted cDNA. The PCR cycling was performed using an ABI StepOne Real-Time Cycler (Applied Biosystems, Framingham, MA, USA) as follows: 3 min initial denaturation at $95^{\circ} \mathrm{C}$ and 40 cycles of amplification at $94^{\circ} \mathrm{C}$ for $30 \mathrm{sec}, 55^{\circ} \mathrm{C}$ for $45 \mathrm{sec}$ and $72^{\circ} \mathrm{C}$ for $45 \mathrm{sec}$. Fluorescence readings were collected at $72^{\circ} \mathrm{C}$. GAPDH amplification was used as an internal control. The $\mathrm{Ct}$ value of each target gene was normalized to the Ct-value of GAPDH by subtracting the GAPDH Ct-value from the target $\mathrm{Ct}$ value. The relative expression levels for each target PCR was calculated using the equation (12): Relative expression= $2^{-[\mathrm{Ct}(\mathrm{target})-\mathrm{Ct}(\mathrm{GAPDH})]} \times 10,000$.

Statistical analysis. SPSS 13.0 software for Windows (SPSS, Inc., Chicago, IL, USA) was used for all statistical analyses. The association between chemokine or chemokine receptor expression and clinicopathologic parameters was analyzed using the $\chi^{2}$ test. Correlations among the levels of chemokine or chemokine receptor messenger (m)RNA expression in tumor tissues were determined using Pearson's correlation coefficient analysis. $\mathrm{P}<0.05$ was considered to indicate a statistically significant difference between values. 
Table I. Gene-specific primers used in reverse transcription quantitative polymerase chain reaction for chemokine-chemokine receptors.

\begin{tabular}{|c|c|c|c|}
\hline Target gene & Primer pairs & Products (bp) & Accession no. \\
\hline CCL19 & $\begin{array}{l}\text { F: 5'TCCCCAGCCCCAACTC 3' } \\
\text { R: 5'TGCGGCGCTTCATCTT 3' }\end{array}$ & 247 & NM_006274 \\
\hline CCL21 & $\begin{array}{l}\text { F: 5'AGGACCCAAGGCAGTGAT 3' } \\
\text { R: 5'CCCTGGGCTGGTTTCTG 3' }\end{array}$ & 248 & NM_002989 \\
\hline CCR7 & $\begin{array}{l}\text { F: 5'CAGAGAGCGTCATGGACC 3' } \\
\text { R: 5'GACCAGCCCATTGCCC 3' }\end{array}$ & 248 & NM_001838 \\
\hline CXCL12/SDF-1 & $\begin{array}{l}\text { F: 5'TCTGCCTCAGCGACGG 3' } \\
\text { R: 5'TTGGCTGTTGTGCTTACTTG 3' }\end{array}$ & 237 & NM_199168 \\
\hline CXCR4 & $\begin{array}{l}\text { F: 5'CCAGTAGCCACCGCATCT 3' } \\
\text { R: 5'TGTCCGTCATGCTTCTCAG 3' }\end{array}$ & 259 & NM_003467 \\
\hline CXCL8/IL8 & $\begin{array}{l}\text { F: 5'CAGCCTTCCTGATTTCTGC 3' } \\
\text { R: 5'AAACTTCTCCACAACCCTCTG 3' }\end{array}$ & 245 & NM_000584 \\
\hline CXCR1/IL8R A & $\begin{array}{l}\text { F: 5'CCCTCTAGCTGTTAAGTCACTCT 3' } \\
\text { R: 5'AACACTAGGGCATAGGCGAT 3' }\end{array}$ & 255 & NM_000634 \\
\hline CXCR2/IL8R B & $\begin{array}{l}\text { F: 5'ACCTCATTGTTCCTCTGTGG 3' } \\
\text { R: 5'TCCTGACTGGGTCGCTG 3' }\end{array}$ & 241 & NM_001557 \\
\hline GAPDH & $\begin{array}{l}\text { F: 5'GTGAAGGTCGGAGTCAACGG 3' } \\
\text { R: 5'CTGGAAGATGGTGATGGGAT 3' }\end{array}$ & 225 & NM_002046 \\
\hline
\end{tabular}

CCL19/21, chemokine (C-C motif) ligand 19/21; CCR7, chemokine (C-C motif) receptor 7; CXCL8/12, chemokine (C-X-C motif) ligand 8/12; CXCR1/2/4, chemokine (C-X-C motif) receptor 1/2/4; SDF-1, stromal cell-derived factor 1; IL8(R), interleukin 8 (receptor); F, Forward; R, reverse.

\section{Results}

Expression of CXCL12/SDF-1 and CXCR4 in lung carcinoma. The immunostaining of CXCR4 and CXCL12/SDF-1 was present in tumor cells and stromal inflammatory cells with no expression evident on alveolar epithelial cells or vascular endothelial cells, whereas staining for CXCL12/SDF-1 appeared weakly in the bronchial epithelial cells. Representative images of immunohistochemical staining of CXCR4 and CXCL12/SDF-1 are shown in Fig. 1A and B, respectively. As shown in Table II, expression of CXCL12/SDF-1 and CXCR4 was detected in $61.7 \%(74 / 120)$ and $28.3 \%(34 / 120)$ of lung carcinomas, respectively. There were no significant differences for the positive percentage of CXCL12/SDF-1 or CXCR4 among different histological subtypes. However, CXCR4 and CXCL12/SDF-1 expression were found to be positively correlated with lymph node metastasis $\left(\chi^{2}=5.36\right.$ and 8.48, respectively; $\mathrm{P}<0.01$ ). No correlations were observed between CXCR4 or CXCL12/SDF-1 and gender, age, tumor grade or differentiation. In addition, there were no significant differences for CXCL12/SDF-1 in different clinicopathological grouping.

In 120 lung carcinoma patients, the average relative expression of CXCR4 and CXCL12/SDF-1 messenger (m)RNA in tumor tissues was 56.24 and 212.63 respectively, which was significantly higher than those in normal lung tissues (6.81 and 78.02, respectively; $\mathrm{P}<0.001)$. In the four histological subtypes, Csc exhibited increased CXCL12/SDF-1 mRNA expression $(\mathrm{P}<0.05)$, whereas Adc expressed higher CXCR4 mRNA levels compared with normal tissues $(\mathrm{P}<0.01)$ (Table II). CXCL12/SDF-1 mRNA expression was significantly associated with higher TNM staging $(\mathrm{P}<0.01)$, which was coincident with the immunohistochemical results. Higher CXCL12/SDF-1 mRNA expression was found in the patients without vascular invasion $(\mathrm{P}<0.01)$, while higher CXCR4 mRNA levels were correlated with lymph node metastasis and vascular invasion $(\mathrm{P}<0.01)$ (Table II).

Expression of CXCL8/IL-8, CXCR1 and CXCR2 in lung carcinoma. Of the 120 tumor samples, 48 (40\%), $40(33 \%)$ and $54(45 \%)$ were positively stained for CXCL8/IL-8, CXCR1 and CXCR2 in tumor cells, respectively. Similarly in the neutrophilic granulocytes of the stroma, weak cytoplasmic staining was observed in certain normal alveolar epithelial cells (Fig. 1C and D). As shown in Table II, the CXCL8/IL-8-positive percentage was significantly higher in lung carcinoma with lymph node metastasis (50 vs. $25 \%$; $\left.\chi^{2}=7.50 ; \mathrm{P}<0.01\right)$. Furthermore, no significant associations were observed between other clinicopathologic characteristics and CXCL8/IL-8, CXCR1 or CXCR2 immunoreactivity.

In all patients, the average relative expression levels of CXCL8/IL-8 and CXCR2 mRNA in tumor tissues were 46.21 and 40.69, respectively, which was significantly increased compared with those in normal lung tissues (13.7 and 19.67, respectively; $\mathrm{P}<0.01)$. However, CXCR1 mRNA expression was lower in lung carcinomas compared with normal tissues (4.98 vs. 27.7; $\mathrm{P}<0.01$ ). In different histological subtypes, Csc exhibited higher CXCR1 mRNA expression, whereas 
Table II. Correlation of chemokine-chemokine receptor expression with clinicopathological characteristics in lung carcinoma.

A, CXCL12/SDF-1 and CXCR4 expression

\begin{tabular}{|c|c|c|c|c|c|}
\hline \multirow[b]{2}{*}{ Characteristic } & \multirow[b]{2}{*}{$\mathrm{N}$} & \multicolumn{2}{|c|}{ CXCL12/SDF-1 } & \multicolumn{2}{|c|}{ CXCR4 } \\
\hline & & Mean \pm Std & $\mathrm{IHC}(\%)$ & Mean \pm Std & $\mathrm{IHC}(\%)$ \\
\hline \multicolumn{6}{|l|}{ Gender } \\
\hline Male & 86 & $231.11 \pm 67.27^{\mathrm{a}}$ & 58.1 & $52.59 \pm 9.01$ & 34.9 \\
\hline Female & 34 & $157.67 \pm 40.89$ & 70.6 & $50.30 \pm 10.41$ & 11.8 \\
\hline \multicolumn{6}{|c|}{ Histological type } \\
\hline Adc & 30 & $237.16 \pm 54.54$ & 80.0 & $116.70 \pm 15.61^{\mathrm{b}}$ & 20.0 \\
\hline Scc & 54 & $175.72 \pm 39.93$ & 59.3 & $28.88 \pm 2.70$ & 33.3 \\
\hline Asc & 24 & $235.09 \pm 47.14$ & 58.3 & $58.23 \pm 7.25$ & 33.3 \\
\hline Csc & 12 & $305.56 \pm 62.66^{\mathrm{a}}$ & 33.3 & $32.19 \pm 5.96$ & 16.7 \\
\hline \multicolumn{6}{|l|}{ TNM staging } \\
\hline I-II & 66 & $196.42 \pm 43.99^{b}$ & 57.6 & $50.65 \pm 5.96$ & 30.3 \\
\hline III-IV & 54 & $242.72 \pm 39.16$ & 66.7 & $54.41 \pm 5.69$ & 25.9 \\
\hline \multicolumn{6}{|c|}{ Lymph node metastasis } \\
\hline $\mathrm{N}=0$ & 48 & $222.60 \pm 64.77$ & $45.8^{b}$ & $42.54 \pm 4.25^{b}$ & $16.7^{\mathrm{a}}$ \\
\hline $\mathrm{N}>0$ & 72 & $207.13 \pm 56.69$ & 72.2 & $65.65 \pm 8.28$ & 36.1 \\
\hline \multicolumn{6}{|c|}{ Vascular invasion } \\
\hline Negative & 48 & $320.82 \pm 63.17^{\mathrm{b}}$ & 66.7 & $20.90 \pm 5.85^{\mathrm{b}}$ & 29.2 \\
\hline Positive & 72 & $212.94 \pm 40.34$ & 58.3 & $84.87 \pm 18.79$ & 27.8 \\
\hline
\end{tabular}

B, CXCL8/IL-8, CXCR1 and CXCR2 expression

\begin{tabular}{|c|c|c|c|c|c|c|c|}
\hline \multirow[b]{2}{*}{ Characteristic } & \multirow[b]{2}{*}{$\mathrm{N}$} & \multicolumn{2}{|c|}{ CXCL8/IL-8 } & \multicolumn{2}{|c|}{ CXCR1 } & \multicolumn{2}{|c|}{ CXCR2 } \\
\hline & & Mean \pm Std & IHC (\%) & Mean \pm Std & $\mathrm{IHC}(\%)$ & Mean \pm Std & $\mathrm{IHC}(\%)$ \\
\hline \multicolumn{8}{|l|}{ Gender } \\
\hline Male & 86 & $41.39 \pm 13.92$ & 37.2 & $5.17 \pm 3.93$ & 32.6 & $45.96 \pm 15.76^{\mathrm{b}}$ & 39.5 \\
\hline Female & 34 & $44.92 \pm 12.44$ & 47.1 & $3.86 \pm 2.50$ & 35.3 & $14.43 \pm 6.03$ & 58.8 \\
\hline \multicolumn{8}{|c|}{ Histological type } \\
\hline Adc & 30 & $63.27 \pm 9.19^{b}$ & 46.7 & $2.03 \pm 1.14$ & 53.3 & $64.02 \pm 18.74^{\mathrm{a}}$ & $73.3^{\mathrm{b}}$ \\
\hline Scc & 54 & $38.54 \pm 8.72$ & 37.0 & $1.98 \pm 0.85$ & 18.5 & $39.58 \pm 14.99$ & 37.0 \\
\hline Asc & 24 & $36.43 \pm 8.22$ & 33.3 & $4.62 \pm 2.43$ & 50.0 & $15.92 \pm 7.25$ & 41.7 \\
\hline $\mathrm{Csc}$ & 12 & $29.61 \pm 6.43$ & 50.0 & $21.20 \pm 8.38^{\mathrm{a}}$ & 16.7 & $24.47 \pm 9.39$ & 16.7 \\
\hline \multicolumn{8}{|l|}{ TNM staging } \\
\hline I-II & 66 & $35.53 \pm 10.13^{\mathrm{a}}$ & 39.4 & $5.61 \pm 2.66$ & 36.4 & $43.87 \pm 15.33^{\mathrm{a}}$ & 42.4 \\
\hline III-IV & 54 & $52.97 \pm 8.35$ & 40.7 & $3.76 \pm 1.41$ & 29.6 & $30.95 \pm 13.70$ & 48.1 \\
\hline \multicolumn{8}{|c|}{ Lymph node metastasis } \\
\hline $\mathrm{N}=0$ & 48 & $38.21 \pm 9.45^{\mathrm{a}}$ & $25.0^{\mathrm{b}}$ & $4.73 \pm 2.49$ & 33.3 & $32.64 \pm 13.65^{\mathrm{a}}$ & $33.3^{\mathrm{b}}$ \\
\hline $\mathrm{N}>0$ & 72 & $44.96 \pm 13.71$ & 50.0 & $5.00 \pm 3.60$ & 33.3 & $43.39 \pm 15.49$ & 52.8 \\
\hline \multicolumn{8}{|c|}{ Vascular invasion } \\
\hline Negative & 48 & $45.37 \pm 6.64$ & 50.0 & $5.14 \pm 1.23$ & $50.0^{\mathrm{b}}$ & $51.06 \pm 14.23$ & 50.0 \\
\hline Positive & 72 & $43.13 \pm 5.44$ & 33.3 & $3.88 \pm 1.71$ & 22.2 & $46.02 \pm 10.04$ & 41.7 \\
\hline
\end{tabular}

C, CCL19, CCL21 and CCR7 expression

\begin{tabular}{|c|c|c|c|c|c|c|c|}
\hline \multirow[b]{2}{*}{ Characteristic } & \multirow[b]{2}{*}{$\mathrm{N}$} & \multicolumn{2}{|c|}{ CCL19 } & \multicolumn{2}{|c|}{ CCL21 } & \multicolumn{2}{|c|}{ CCR7 } \\
\hline & & Mean \pm Std & IHC (\%) & Mean \pm Std & $\mathrm{IHC}(\%)$ & Mean \pm Std & $\mathrm{IHC}(\%)$ \\
\hline \multicolumn{8}{|l|}{ Gender } \\
\hline Male & 86 & $47.55 \pm 6.97$ & 43.0 & $9.52 \pm 3.66$ & 16.3 & $30.16 \pm 13.37$ & 39.5 \\
\hline Female & 34 & $49.99 \pm 5.11$ & 47.1 & $10.44 \pm 3.78$ & 20.6 & $26.31 \pm 9.03$ & 35.3 \\
\hline
\end{tabular}


Table II. Continued.

\begin{tabular}{|c|c|c|c|c|c|c|c|}
\hline \multirow[b]{2}{*}{ Characteristic } & \multirow[b]{2}{*}{$\mathrm{N}$} & \multicolumn{2}{|c|}{ CCL19 } & \multicolumn{2}{|c|}{ CCL21 } & \multicolumn{2}{|c|}{ CCR7 } \\
\hline & & Mean \pm Std & $\mathrm{IHC}(\%)$ & Mean \pm Std & IHC (\%) & Mean \pm Std & $\mathrm{IHC}(\%)$ \\
\hline \multicolumn{8}{|c|}{ Histological type } \\
\hline Adc & 30 & $143.50 \pm 20.55^{\mathrm{b}}$ & $66.7^{\mathrm{b}}$ & $9.76 \pm 2.81$ & 20.0 & $18.08 \pm 4.92^{\mathrm{a}}$ & 40.0 \\
\hline Scc & 54 & $25.08 \pm 3.40$ & 31.5 & $7.85 \pm 2.58$ & 16.7 & $33.38 \pm 13.27$ & 40.7 \\
\hline Asc & 24 & $12.99 \pm 1.27$ & 33.3 & $13.32 \pm 3.95^{\mathrm{a}}$ & 20.8 & $23.40 \pm 9.93$ & 33.3 \\
\hline $\mathrm{Csc}$ & 12 & $11.47 \pm 0.81$ & 25.0 & $6.55 \pm 2.44$ & 25.0 & $21.17 \pm 11.97$ & 33.3 \\
\hline \multicolumn{8}{|l|}{ TNM staging } \\
\hline I-II & 66 & $39.75 \pm 15.29^{a}$ & 40.9 & $8.59 \pm 2.56$ & 15.2 & $30.79 \pm 13.29^{\mathrm{a}}$ & 36.4 \\
\hline III-IV & 54 & $55.81 \pm 18.73$ & 48.1 & $9.52 \pm 4.89$ & 20.4 & $21.09 \pm 12.09$ & 40.7 \\
\hline \multicolumn{8}{|c|}{ Lymph node metastasis } \\
\hline $\mathrm{N}=0$ & 48 & $52.79 \pm 17.21^{\mathrm{a}}$ & 41.7 & $8.49 \pm 3.60$ & 12.5 & $36.42 \pm 14.35^{\mathrm{a}}$ & 37.5 \\
\hline $\mathrm{N}>0$ & 72 & $41.01 \pm 15.99$ & 45.8 & $9.27 \pm 4.75$ & 20.8 & $20.53 \pm 11.89$ & 38.9 \\
\hline \multicolumn{8}{|c|}{ Vascular invasion } \\
\hline Negative & 48 & $12.01 \pm 4.24^{\mathrm{b}}$ & 37.5 & $10.61 \pm 3.03$ & 16.7 & $13.84 \pm 2.07$ & 54.2 \\
\hline Positive & 72 & $70.52 \pm 22.86$ & 48.6 & $10.75 \pm 4.55$ & 18.1 & $44.31 \pm 10.97^{b}$ & $27.8^{\mathrm{b}}$ \\
\hline
\end{tabular}

Values are presented as the mean \pm std and are expressed relative to that of the housekeeping gene GAPDH. IHC results are presented as the positive percentage of each group. ${ }^{a} \mathrm{P}<0.05$ and ${ }^{\mathrm{b}} \mathrm{P}<0.01$ and between groups. CXCL8/12, chemokine (C-X-C motif) ligand 8/12; SDF-1, stromal cell-derived factor 1; IL-8, interleukin 8; CCL19/21, chemokine (C-C motif) ligand 19/21; CXCR1/2/4, chemokine (C-X-C motif) receptor 1/2/4; CCR7, chemokine (C-C motif) receptor 7; Std, standard deviation; IHC, immunohistochemistry; Adc, adenocarcinoma; Scc, squamous cell carcinoma; Asc, adenosquamous carcinoma; Csc, combined small-cell carcinoma; TNM, tumor-node-metastasis.

A

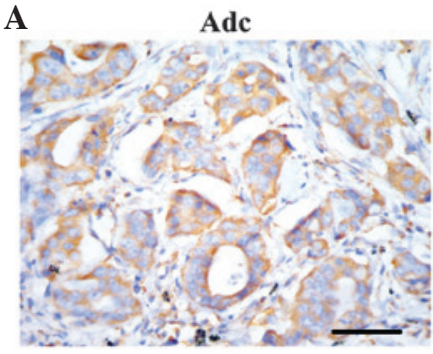

$\mathrm{C}$
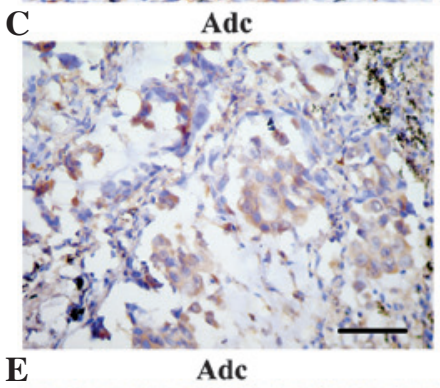

$\mathbf{E}$ Ade

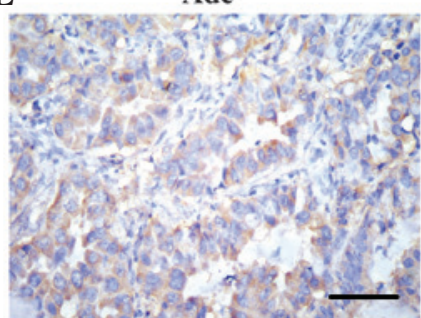

Scc

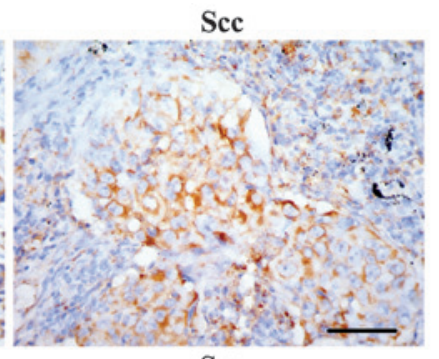

Scc

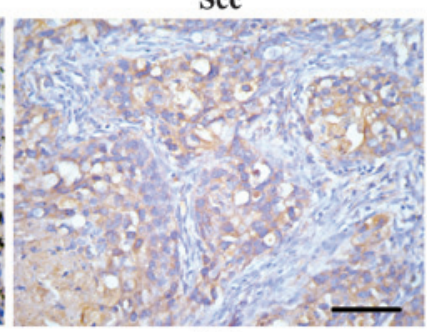

Scc

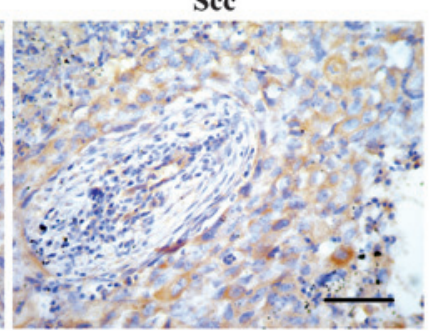

B

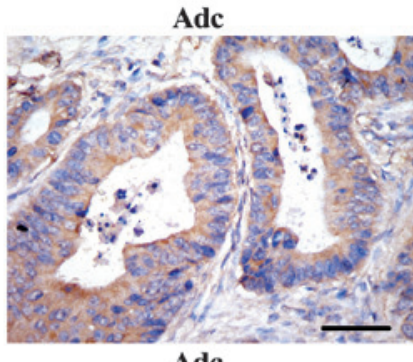

D

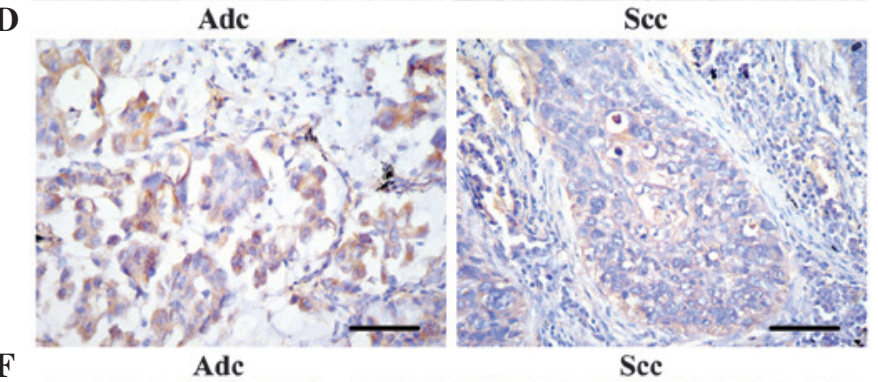

$\mathbf{F}$



Figure 1. Representative photomicrograph of immunolocalization of chemokines and chemokine receptors in lung Adc and Scc tissues. (A) Positive staining of CXCR4 was identified in the membrane and cytoplasm of cancer cells; and (B) CXCL12/stromal cell-derived factor 1 was primarily located in the cytoplasm of the cancer cells. (C and D) CXCR2 and CXCL8/interleukin 8 were detected in the cytoplasm of cancer cells and surrounding stromal tissues. (E) Positive staining of CCR7 was presented in the membrane and cytoplasm of cancer cells; and (F) immunoreactivity of CCL19 was located in the cytoplasm, the staining of which was more prominent in Adc tissue. Magnification, x400; scale bars, $50 \mu \mathrm{m}$. Adc, adenocarcinoma; Scc, squamous cell carcinoma. CXCR1/2/4, chemokine (C-X-C motif) receptor 1/2/4; CXCL8/12, chemokine (C-X-C motif) ligand 8/12; CCR7, chemokine (C-C motif) receptor 7; CCL19/21, chemokine (C-C motif) ligand 19/21. 
Adc demonstrated higher CXCL8/IL-8 and CXCR2 mRNA expression $(\mathrm{P}<0.05)$ (Table II). CXCL8/IL-8 or CXCR2 mRNA expression levels, but not CXCR1, were associated with a high incidence of lymph node metastasis $(\mathrm{P}<0.05)$, which was coincident with the immunohistochemical staining results. A strong positive correlation was substantiated between CXCL8/IL-8 mRNA expression with TNM staging $(\mathrm{P}<0.05)($ Table II). By contrast, a negative correlation was identified between CXCR2 mRNA expression and TNM staging $(\mathrm{P}<0.05)$ (Table II). These results suggested the crucial role of CXCL8/IL-8 and CXCR2 in tumor progression of lung carcinoma, without the involvement of CXCR1.

Expression of CCL19, CCL21 and CCR7 in lung carcinoma. The majority of CCL21 immunostaining in the tumor islets was weak in inflammatory cells and tumor epithelial cells. Moderate immunostaining of CCL19 and CCR7 was detected in the cytoplasm of tumor cells and stromal inflammatory cells, whereas weak expression was evident in normal bronchial and alveolar epithelial cells. Furthermore, CCR7 was found to be expressed on the membrane of certain tumor cells (Fig. 1E and F). A total of $44.2 \%$ (53/120), $28 \%(21 / 120)$ and $38.3 \%$ (46/120) tumor samples were positively stained with CCL19, CCL21 and CCR7, respectively. As shown in Table II, staining intensity and positive percentage of CCL19 were higher in adenocarcinoma $\left(66.7 \% ; \chi^{2}=12.09 ; \mathrm{P}<0.01\right)$. However, no significant correlations were identified between the clinicopathologic characteristics and the positivity of CCR7 or CCL21.

The average relative expression levels of CCL19 and CCR7 mRNA in tumor tissues were 48.31 and 36.24 , respectively, which was significantly higher compared with those in normal lung tissues (10.22 and 10.29, respectively; $\mathrm{P}<0.001$ ). However, CCL21 mRNA expression was low in lung carcinoma and normal tissues (9.48 and 11.09, respectively). Compared with other histological subtypes, Adc exhibited the highest CCL19 mRNA expression and the lowest CCR7 mRNA expression $(\mathrm{P}<0.05)$. By contrast, Asc had markedly increased CCL21 mRNA expression compared with the other subtypes $(\mathrm{P}<0.05)($ Table II). Tumor staging was inversely correlated with CCR7 mRNA expression and positively correlated with CCL19 mRNA expression $(\mathrm{P}<0.05)$. Furthermore, the mRNA expression of CCL19 and CCR7 was negatively correlated with lymph node metastasis $(\mathrm{P}<0.05)$ and positively correlated with vessel invasion $(\mathrm{P}<0.01)$ (Table II). No correlation was observed between CCR7 expression and gender, histology, staging or metastasis (Table II).

\section{Discussion}

The human chemokines superfamily consists of 48 chemoattractant cytokines, which are known to form interactions with 19 different $G$ protein-coupled chemokine receptors (2). Chemokine ligands are small secreted proteins that are released in response to cell activation by various cytokines or pathological stimuli. There are four sub-families of chemokines, $\mathrm{C}, \mathrm{C}-\mathrm{C}, \mathrm{C}-\mathrm{X}-\mathrm{C}$ and $\mathrm{C}-\mathrm{X}_{3-} \mathrm{C}$ ), which are classified according to cysteine residue spacing proximal to the $\mathrm{N}$ terminus of these chemokines. It has been reported that certain chemokines and their receptors may have important functions in tumorigenesis and/or metastasis (4). It was suggested that chemokine receptors may enable tumor dissemination at numerous stages during metastasis, including tumor cell adherence to the endothelium, blood vessels extravasation, metastatic colonization, angiogenesis, proliferation and immune response evasion via activation of key survival pathways $(3,4)$.

The most prevalent chemokine receptor, CXCR4, has been reported to be overexpressed in human cancers. CXCL12/SDF-1, the only ligand of CXCR4, is a homeostatic chemokine and is continuously produced in numerous types of tissues, including those where metastases commonly occur (6). CXCL12/SDF-1 interactions with CXCR4 initiate divergent downstream signaling pathways, which may lead to various responses, including chemotaxis, cell survival and/or proliferation, increased intracellular calcium levels and gene transcription. A previous in vitro and in vivo study reported that CXCL12-CXCR4 interactions in the tumor microenvironment may promote local tumor growth; in addition, elevated CXCR4 expression in tumor cells was suggested to enhance the invasive and metastatic potential of these cells (13). A previous preclinical trial demonstrated that anti-SDF-1 or anti-CXCR4 monoclonal antibodies have been reported to neutralize SDF-1 in vivo and result in a significant decrease in non-small-cell lung cancer (NSCLC) metastases (14). At present, $>15$ novel drugs are being developed, which target the CXCL12/CXCR4 axis; one of these drugs, AMD3100 (also known as Plerixafor and Mozobil), has gained Food and Drug Administration approval (15). In the present study, the expression of CXCR4 and CXCL12/SDF-1 mRNA in tumor tissues was significantly increased compared with that in normal lung tissues, although the latter demonstrated low-level constitutive CXCL12/SDF-1 expression.

As demonstrated in retrospective studies of human metastatic cancers, elevated CXCL12/CXCR4 expression was associated with advanced diseases stages and with poorer prognoses $(13,16)$. Franco et al $(17)$ reported that increased CXCR4 expression in lung carcinoma cells was associated with a marked elevation in the microvascular structure density of tumors, which was in turn associated with increased microvessel invasion by tumor cells. In the present study, it was observed that higher CXCR4 mRNA expression occurred in lung carcinomas with lymph node metastasis or with vascular invasion, which was in concurrence with the previous consensus of the role of CXCR4 in promotion of invasion and metastasis $(13,17,18)$. Previous studies have reported an association between high CXCL12/SDF-1 expression and high T scores as well as an increased tendency to form lymph node metastases $(18,19)$. In the present study, CXCL12/SDF-1 mRNA expression was significantly associated with higher TNM staging, but inversely correlated with vascular invasion. This indicated that CXCL12/SDF-1 was a potential marker of tumor progression. Although these are preliminary results and require further validation, they indicated that the CXCL12-CXCR4 axis was activated in lung carcinoma and may have important roles in tumor differentiation, invasion and metastasis.

CXCL8/IL-8 is critical for the neovascularization required for the initiation and maintenance of tumor growth, which is associated with metastasis (8). A previous study reported a 4-fold increase in IL-8 levels in human tissue homogenates of non-small-cell bronchogenic carcinoma compared with normal lung tissue (20). In addition, Yuan et al (21) demonstrated 
that IL-8 mRNA expression in NSCLC exhibited a marked association with tumor progression, tumor angiogenesis, survival and time to relapse, which suggested IL-8 may be used as a prognostic indicator (21). In the present study, weak cytoplasmic staining was observed in certain normal alveolar epithelial cells, while CXCL8/IL-8 mRNA expression was significantly greater in tumor tissue; in particular, in lung adenocarcinomas. High expression of IL-8 was highly associated with TNM staging and lymph node metastasis, as determined using immunohistochemistry and RT-qPCR; however, no correlation was identified between the expression of IL-8 and vessel invasion.

CXCR1 and CXCR2 are two closely associated receptors that regulate the biological activity of CXCL8/IL-8. CXCR1 only interacts with IL-8 and CXCL6, whereas CXCR2 is able to interact with all known angiogenic $\mathrm{CXC}$ chemokines containing the Glu-Leu-Arg motif, including CXCL8/IL-8. The presence of CXCR1 and CXCR2 has been detected on numerous types of normal cells, including inflammatory and endothelial cells. However, the function of CXCR1 and CXCR2 in IL-8-mediated activity remains to be fully elucidated as previous results were controversial. Zhu et al (8) reported a significant reduction in cell proliferation due to the presence of anti-CXCR1 antibodies, although this was not observed with anti-CXCR2 antibodies; this therefore suggested that CXCR1 was the primary receptor involved in mediating the mitogenic function of IL-8 in lung cancer (8). By contrast, a murine model was used to demonstrate that the attenuation of CXCR2 inhibited tumor growth and angiogenesis in lung cancer (22). In the present study, the simultaneous expression of IL-8 and its receptors was investigated in a large number of lung carcinoma tissue samples. The results revealed that CXCR2 mRNA expression was significantly elevated in tumor tissues compared with normal lung tissues, while lung carcinomas produced low or undetectable levels of CXCR1 mRNA. In addition, it was demonstrated that the expression of CXCR 1 mRNA was increased in Csc and CXCR2 mRNA expression was elevated in Adc. This therefore indicated that CXCL8/IL-8 was able to mediate different receptor activation in different types of lung carcinoma; however, more samples of Csc are required to confirm this conclusion. A previous study reported evidence of crosstalk between the IL- 8 and epidermal growth factor receptor (EGFR); in addition, EGFR-induced Ras activation promoted the expression of CXCL8/IL-8 and CXCL1 in tumor cells (23). Therefore, these chemokines were found to promote tumor cell proliferation via autocrine loops and promote tumor-associated angiogenesis through CXCR2 in a paracrine manner (24). In the present study, CXCR2 mRNA expression levels, but not CXCR1, were found to be associated with a high incidence of lymph node metastasis and high TNM staging. This may indicate that IL- 8 functions as an autocrine and/or paracrine growth factor in lung carcinoma and promoted lymphatic metastasis via the mediation of CXCR2.

The CCR7-CCL19/CCL21 axis has been well-characterized for its crucial role in the formation of secondary lymphoid structures under physiological conditions (25). In cancer, the CCR7-CCL19/CCL21 axis is primarily responsible for lymph node metastasis formation by recruiting tumor cells to the T cell zone of lymph nodes (25). CCR7 overexpression has been observed in a large number of malignant tumors, including esophageal squamous cell carcinoma, gastric carcinoma, colon carcinoma and NSCLC, which was confirmed to be associated with lymph node metastasis, tumor growth, angiogenesis and invasion $(6,26,27)$. However, the underlying mechanisms of these associations remained to be elucidated, although they were thought to involve integrins or phosphoinositide 3-kinase $(26,28)$. In present study, higher mRNA expression of CCR7 was observed in tumor tissues compared with normal lung tissues. In addition, CCR7 expression was positively correlated with vascular invasion and negatively correlated with tumor staging and lymph node metastasis. These results seemed to be discordant with those of previous studies $(10,27)$. One previous study reported that high CCR7 expression improved the postoperative prognosis of lung adenocarcinoma patients (29). The role of CCR7 in lung cancer appears to be complex and post-transcription regulation of CCR7 may be important in the progression and metastasis of lung cancer. For example, Su et al (30) reported that CCR7 was a sialylated protein; sialylation has a critical role in paracrine stimulation via the endogenous ligand CCL19. In addition, it was demonstrated that the inhibition of aberrant sialylation of CCR7 attenuated proliferation and invasion as well as promoted apoptosis in breast cells (30).

Cancer cells of several tumors have been reported to upregulate CCR7 and disseminate from the primary tumor, which was suggested to occur through sensing the immobilized CCL21 gradient and actively migrating towards the next lymphatic vessel (25). Shields et al (31) demonstrated that numerous types of cancer secreted CCL21, which may mediate lymphoid tissue neogenesis; in addition, it was proposed that CCL21-secreting tumors were able to shift the host immune response from immunogenic to tolerogenic, a phenomenon that facilitates tumor progression (31). Koizumi et al (32) demonstrated CCL21-induced migration in vitro and the metastatic behavior of human NSCLC in an animal model. In the present study, $28 \%$ of lung cancer specimens were positively stained for CCL21, which was primarily presented in inflammatory cells. CCL21 mRNA expression was at a relatively low level in lung carcinomas and normal tissues. In addition, constitutive expression of CCL21 was detected in interstitial inflammatory cells and endothelial cells.

Zhang et al (33) reported that CCL19/CCR7 upregulated the expression of heparanase via specificity protein-1 and contributed to the invasion of A549 cells. In addition, other previous studies have demonstrated that CCL19 had an antitumor role in colorectal cancer and acted as a promising clinical prognostic factor for lung adenocarcinoma, as well as CCR7 (29,34). As a potential immune stimulator, the antitumor activity of CCL19 was determined in a transplantable model for lung cancer through injecting recombinant CCL19 intratumorally, which led to significant systemic reduction in tumor volumes $(35,36)$. The present study observed increased expression of CCL19 in lung cancer and an association between CCL19 expression and high TNM staging or vascular invasion. By contrast, a negative correlation was identified between CCL19 expression and lymph node metastasis. This indicated that, as the predominant ligand of CCR7, CCL19 may serve as an indicator of tumor progression and the CCL19/CCR7 axis may have an important role in hematogenous metastasis, instead of lymphatic metastasis in lung cancer. 
In conclusion, the chemotactic interaction between CXCR4 and CXCL12/SDF-1, CXCR2 and CXCL8/IL8 as well as CCR7 and CCL19, may be potent mechanisms for the induction of tumor differentiation, lymph node metastasis and vascular invasion in lung carcinoma. Chemokines, including CXCL12/SDF-1, CXCL8/IL8 and CCL19, may function as autocrine and/or paracrine growth factors, which are indicative of tumor progression and higher TNM staging. Furthermore, CXCR4 and CXCR2 promoted lymphatic metastasis through the activation of their specific ligands, while CCL19 and its receptor CCR7 had an essential role in hematogenous metastasis of lung carcinoma. These findings suggested that chemokine receptors may be useful antitumor targets in controlling lymph node metastasis and vascular invasion for lung cancer therapy.

\section{Acknowledgements}

The present study was supported by a grant awarded to Dr Yan Liu by the Science \& Technology Foundation of Tianjin Health Bureau, China (no. ky0702).

\section{References}

1. Jemal A, Siegel R, Xu J and Ward E: Cancer statistics, 2010. CA Cancer J Clin 60: 277-300, 2010.

2. Saintigny $P$ and Burger JA: Recent advances in non-small cell lung cancer biology and clinical management. Discov Med 13: 287-297, 2012

3. Zlotnik A, Burkhardt AM and Homey B: Homeostatic chemokine receptors and organ-specific metastasis. Nat Rev Immunol 11: 597-606, 2011.

4. Kakinuma T and Hwang ST: Chemokines, chemokine receptors and cancer metastasis. J Leukoc Biol 79: 639-651, 2006.

5. Keeley EC, Mehrad B and Strieter RM: CXC chemokines in cancer angiogenesis and metastases. Adv Cancer Res 106: 91-111, 2010.

6. Wald O, Shapira OM and Izhar U: CXCR4/CXCL12 axis in non small cell lung cancer (NSCLC) pathologic roles and therapeutic potential. Theranostics 3: 26-33, 2013.

7. Teicher BA and Fricker SP: CXCL12 (SDF-1)/CXCR4 pathway in cancer. Clin Cancer Res 16: 2927-2931, 2010.

8. Zhu YM, Webster SJ, Flower D and Woll PJ: Interleukin-8/CXCL8 is a growth factor for human lung cancer cells. Br J Cancer 91: 1970-1976, 2004.

9. Wiley HE, Gonzalez EB, Maki W, Wu MT and Hwang ST: Expression of $\mathrm{CC}$ chemokine receptor-7 and regional lymph node metastasis of B16 murine melanoma. J Natl Cancer Inst 93: 1638-1643, 2001.

10. Mashino K, Sadanaga N, Yamaguchi H, et al: Expression of chemokine receptor CCR7 is associated with lymph node metastasis of gastric carcinoma. Cancer Res 62: 2937-2941, 2002

11. Tsim S, O'Dowd CA, Milroy R and Davidson S: Staging of non-small cell lung cancer (NSCLC): A review. Respir Med 104: 1767-1774, 2010.

12. Livak KJ and Schmittgen TD: Analysis of relative gene expression data using real-time quantitative PCR and the 2(-Delta Delta C(T)) Method. Methods 25: 402-408, 2001.

13. Su L, Zhang J, Xu H, Wang Y, Chu Y, Liu R and Xiong S: Differential expression of CXCR4 is associated with the metastatic potential of human non-small cell lung cancer cells. Clin Cancer Res 11: 8273-8280, 2005.

14. Villena V,López-Encuentra A, García-Luján R,Echave-Sustaeta J and Martínez CJ: Clinical implications of appearance of pleural fluid at thoracentesis. Chest 125: 156-159, 2004.

15. Brave M, Farrell A, Ching Lin S, et al: FDA review summary: Mozobil in combination with granulocyte colony-stimulating factor to mobilize hematopoietic stem cells to the peripheral blood for collection and subsequent autologous transplantation. Oncology 78: 282-288, 2010.
16. Burger JA, Stewart DJ, Wald O and Peled A: Potential of CXCR4 antagonists for the treatment of metastatic lung cancer. Expert Rev Anticancer Ther 11: 621-630, 2011.

17. Franco R, Pirozzi G, Scala S, et al: CXCL12-binding receptors expression in non-small cell lung cancer relates to tumoral microvascular density and CXCR4 positive circulating tumoral cells in lung draining venous blood. Eur J Cardiothorac Surg 41: 368-375, 2012.

18. Wagner PL, Hyjek E, Vazquez MF, et al: CXCL12 and CXCR4 in adenocarcinoma of the lung: association with metastasis and survival. J Thorac Cardiovasc Surg 137: 615-621, 2009.

19. Wald O, Izhar U, Amir G, et al: Interaction between neoplastic cells and cancer-associated fibroblasts through the CXCL12/CXCR4 axis: Role in non-small cell lung cancer tumor proliferation. J Thorac Cardiovasc Surg 141: 1503-1512, 2011.

20. Yatsunami J, Tsuruta N, Ogata K, et al: Interleukin-8 participates in angiogenesis in non-small cell, but not small cell carcinoma of the lung. Cancer Lett 120: 101-108, 1997.

21. Yuan A, Yang PC, Yu CJ, Chen WJ, Lin FY, Kuo SH and Luh KT: Interleukin-8 messenger ribonucleic acid expression correlates with tumor progression, tumor angiogenesis, patient survival and timing of relapse in non-small-cell lung cancer. Am J Respir Crit Care Med 162: 1957-1963, 2000.

22. Keane MP, Belperio JA, Xue YY, Burdick MD and Strieter RM: Depletion of CXCR2 inhibits tumor growth and angiogenesis in a murine model of lung cancer. J Immunol 172: 2853-2860, 2004.

23. Sparmann A and Bar-Sagi D: Ras-induced interleukin- 8 expression plays a critical role in tumor growth and angiogenesis. Cancer Cell 6: 447-458, 2004.

24. Gerber PA, Hippe A, Buhren BA, Müller A and Homey B: Chemokines in tumor-associated angiogenesis. Biol Chem 390: 1213-1223, 2009.

25. Legler DF, Uetz-von Allmen E and Hauser MA: CCR7: Roles in cancer cell dissemination, migration and metastasis formation. Int J Biochem Cell Biol 54: 78-82, 2014.

26. Wang J, Zhang X, Thomas SM, Grandis JR, Wells A, Chen ZG and Ferris RL: Chemokine receptor 7 activates phosphoinositide-3 kinase-mediated invasive and prosurvival pathways in head and neck cancer cells independent of EGFR. Oncogene 24: 5897-5904, 2005.

27. Takanami I: Overexpression of CCR7 mRNA in nonsmall cell lung cancer: Correlation with lymph node metastasis. Int J Cancer 105: 186-189, 2003.

28. Li P, Liu F, Sun L, et al: Chemokine receptor 7 promotes cell migration and adhesion in metastatic squamous cell carcinoma of the head and neck by activating integrin $\alpha v \beta 3$. Int J Mol Med 27: 679-687, 2011.

29. Itakura M, Terashima Y, Shingyoji M, et al: High CC chemokine receptor 7 expression improves postoperative prognosis of lung adenocarcinoma patients. Br J Cancer 109: 1100-1108, 2013.

30. Su ML, Chang TM, Chiang CH, Chang HC, Hou MF, Li WS and Hung WC: Inhibition of chemokine (C-C motif) receptor 7 sialylation suppresses CCL19-stimulated proliferation, invasion and anti-anoikis. PLoS One 9: e98823, 2014.

31. Shields JD, Kourtis IC, Tomei AA, Roberts JM and Swartz MA: Induction of lymphoidlike stroma and immune escape by tumors that express the chemokine CCL21. Science 328: 749-752, 2010.

32. Koizumi K, Kozawa Y, Ohashi Y, et al: CCL21 promotes the migration and adhesion of highly lymph node metastatic human non-small cell lung cancer Lu-99 in vitro. Oncol Rep 17: 1511-1516, 2007.

33. Zhang Q, Sun L, Yin L, Ming J, Zhang S, Luo W and Qiu X: CCL19/CCR7 upregulates heparanase via specificity protein-1 (Sp1) to promote invasion of cell in lung cancer. Tumour Biol 34: 2703-2308, 2013.

34. Lu J, Zhao J, Feng H, et al: Antitumor efficacy of CC motif chemokine ligand 19 in colorectal cancer. Dig Dis Sci 59: 2153-2162, 2014.

35. Hillinger S, Yang SC,Zhu L, et al: EBV-induced molecule 1 ligand chemokine (ELC/CCL19) promotes IFN-gamma-dependent antitumor responses in a lung cancer model. J Immunol 171: 6457-6465, 2003.

36. Hillinger S, Yang SC, Batra RK, Strieter RM, Weder W, Dubinett SM and Sharma S: CCL19 reduces tumour burden in a model of advanced lung cancer. Br J Cancer 94: 1029-1034, 2006. 